\title{
Re-Evaluating the Protective Effect of Hemodialysis Catheter Locking Solutions in Hemodialysis Patients
}

\author{
Chang-Hua Chen ${ }^{1,2,3,4, *}$, Yu-Min Chen ${ }^{5}$, Yu Yang ${ }^{6}$, Yu-Jun Chang ${ }^{7}$, Li-Jhen Lin ${ }^{2}$ and \\ Hua-Cheng Yen ${ }^{8}$ \\ 1 Division of Infectious Disease, Department of Internal Medicine, Changhua Christian Hospital, \\ Changhua 500, Taiwan \\ 2 Center for Infection Prevention and Control, Changhua Christian Hospital, Changhua 500, Taiwan; \\ 3344@cch.org.tw \\ 3 Program in Translational Medicine, National Chung Hsing University, Taichung County 402, Taiwan \\ 4 Rong Hsing Research Center for Translational Medicine, National Chung Hsing University, \\ Taichung County 402, Taiwan \\ 5 Department of Pharmacy, Changhua Christian Hospital, Changhua 500, Taiwan; 30855@cch.org.tw \\ 6 Division of Nephrology, Department of Internal Medicine, Changhua Christian Hospital, Changhua 500, \\ Taiwan; 2219@cch.org.tw \\ 7 Epidemiology and Biostatistics Center, Changhua Christian Hospital, Changhua 500, Taiwan; \\ 83686@cch.org.tw \\ 8 Department of Neurosurgery, Changhua Christian Hospital, Changhua 500, Taiwan; 90211@cch.org.tw \\ * Correspondence: chenchanghuachad@gmail.com; Tel.: +886-4-723-8595-4080
}

Received: 5 March 2019; Accepted: 20 March 2019; Published: 25 March 2019

\begin{abstract}
Catheter-related bloodstream infections (CRBSIs) and exit-site infections (ESIs) are common complications associated with the use of central venous catheters for hemodialysis. The aim of this study was to analyze the impact of routine locking solutions on the incidence of CRBSI and ESI, in preserving catheter function, and on the rate of all-cause mortality in patients undergoing hemodialysis. We selected publications (from inception until July 2018) with studies comparing locking solutions for hemodialysis catheters used in patients undergoing hemodialysis. A total of 21 eligible studies were included, with a total of 4832 patients and 318,769 days of catheter use. The incidence of CRBSI and ESI was significantly lower in the treated group (citrate-based regimen) than in the controls (heparin-based regimen). No significant difference in preserving catheter function and all-cause mortality was found between the two groups. Our findings demonstrated that routine locking solutions for hemodialysis catheters effectively reduce the incidence of CRBSIs and ESIs, but our findings failed to show a benefit for preserving catheter function and mortality rates. Therefore, further studies are urgently needed to conclusively evaluate the impact of routine locking solutions on preserving catheter function and improving the rates of all-cause mortality.
\end{abstract}

Keywords: effect; protection; catheter; hemodialysis; meta-analysis; trial sequential analysis

\section{Introduction}

1.1. Variety of New Strategies for Locking Solutions to Avoid Catheter Infection and Catheter Malfunction in Hemodialysis Patients

Infections are widely prevalent in patients on chronic hemodialysis, and mortality from infection account for $10 \%$ of deaths observed in patients undergoing hemodialysis [1]. The use of central venous catheters in hemodialysis has been associated with catheter-related bloodstream infections (CRBSIs) and exit-site infections (ESIs) [2-4]. Although recent efforts have minimized the use of 
catheters, the proportion patients with end-stage renal disease undergoing dialysis using central venous catheters has not yet declined [5]. Protective strategies against CRBSI and catheter malfunction are necessary [6], and to this end, the use of heparin as a routine locking solution for central venous catheters has become an accepted clinical practice [4]. However, heparinized locking solutions might cause unintended complications, such as systemic anticoagulation effects, bleeding episodes, heparin-induced thrombocytopenia, and susceptibility to bacterial biofilm formation [7-9]. A variety of new locking solutions have been developed; this includes citrate, which has antimicrobial properties [10-12]. However, the disadvantages of citrate compared with heparin have been raised and included the ability of avoiding catheter malfunction, citrate toxicity, and induction of cardiac arrhythmia [13]. Weijmer et al. showed that a 30\% citrate solution was superior to heparin in preventing CRBSI [14]. In contrast, other studies have reported that the use of citrate does not have an advantage over heparin in preventing CRBSI [4,12]. Currently, the findings of the studies comparing citrate with heparin locking solutions are inconclusive for protecting against CRBSI and ESI and preserving the catheter function. Clinicians question if locking solutions should be considered a modifiable risk factor for CRBSIs in patients undergoing hemodialysis. Furthermore, the recommended locking solution for the routine care of patients undergoing hemodialysis continue to remain questionable.

\subsection{Rationale for Re-Evaluating the Protective Effect of Hemodialysis Catheter Locking Solutions in Hemodialysis Patients}

Routine locking solutions for hemodialysis catheters are recommended with category II evidence according to the guideline by the Healthcare Infection Control Practices Advisory Committee in 2011 [15]; however, there are some limitations of the studies providing the current and update evidence. Mostly, conclusions of meta-analysis could be influenced by the heterogeneity between individual studies and insufficient information size. Quantification of the required information size [16] is important to ensure the reliability of the data. In addition, current meta-analyses lack information size calculation [17-24]. Additionally, the incidence of CRBSI is difficult to evaluate because of their subjectivity for case finding, lack of specificity, and high inter-observer variability. CRBSI is associated with high morbidity and mortality in patients undergoing hemodialysis [1], and the prevention of CRBSI and ESI is becoming increasingly essential. Given these limitations, we performed a meta-analysis and trial sequential analysis to assess the impact of routine locking solutions on the incidence of CRBSI and ESI, in preserving catheter function, and on the rate of all-cause mortality in patients undergoing hemodialysis. We grouped the eligible publications according to combination regimen, antimicrobial activity, and concentration of the locking solutions; thereafter, we grouped according to the study design to assess its potential effect on the reported outcomes.

\section{Experimental Section}

\subsection{Search Strategy and Inclusion Criteria}

The study was conducted in accordance with the Declaration of Helsinki, and the protocol was approved by the institutional review board of Changhua Christian Hospital (CCH IRB No. 180801). From the earliest record to July 2018, we searched PubMed, Scopus, Cochrane Central Register of Controlled Trials, Cochrane Database of Systematic Reviews, ClinicalTrials.gov, Embase, and Web of Science databases for studies on locking solutions for central venous catheters used in hemodialysis of patients. Full search strategies for each database are available in the Appendix A. The reference lists of the eligible publications were manually reviewed for relevant studies. Articles published in languages other than English or those with no available full text were excluded.

We included all trials and studies that provided data on one or more of our target outcomes for both the treated group and control group: CRBSIs and ESIs. Two investigators (CHC and YMC) independently reviewed potential trials and studies for inclusion. Disagreements were resolved 
by consensus. We also tried to contact the corresponding authors of selected papers to provide clarifications and missing data where needed.

\subsection{Definition of Study Outcomes}

Based on the original studies, the treated group comprised of patients undergoing hemodialysis using citrate as the locking solution for central venous catheters; for the control group heparin was used as the locking solution (Table 1). The outcomes of the original studies were included in this meta-analysis. The primary outcomes included (1) CRBSI, defined as bacteremia caused by an intravenous catheter, and (2) ESI, defined as the development of a purulent redness around the exit site that did not result from residual stitches. The secondary outcomes included (1), the need to remove the catheter due to catheter malfunction; and (2) the need for thrombolytic treatments due to catheter malfunction; and (3) all-cause mortality at any timeframe. Incidence was presented as the number of episodes per catheter or per patient depending on the available data.

\subsection{Data Extraction and Quality Assessment}

Two reviewers examined all retrieved articles and extracted data using a pre-determined form, recording the name of the first author, year of publication, country where the study was conducted, study design (RCT or observational studies), demographic and disease characteristics of participants, number of participants enrolled, and quality assessment of each study. Each reviewer independently evaluated the quality of the eligible studies, using Jadad scoring [25] for the RCTs and the Newcastle-Ottawa quality assessment scale [26] for the comparative experimental studies.

\subsection{Data Synthesis and Analysis}

The outcomes were measured by determining the odds ratios (ORs). A random effects model was used to pool individual ORs. Analyses were performed with the Comprehensive Meta-Analysis software version 3.0 (Biostat, Englewood, NJ, USA). Between-trial heterogeneity was determined using $I^{2}$ tests; values $>50 \%$ were regarded as considerable heterogeneity [27]. Funnel plots and Egger's test were used to examine potential publication bias [27]. Statistical significance was defined as $p<0.05$, except for the determination of publication bias where $p<0.10$ was considered significant. This study was conducted and reported in accordance with the Preferred Reporting Items for Systematic Reviews and Meta-Analyses (PRISMA) statement (Table S1) [28].

In trial sequential analyses, the inconsistence of heterogeneity $\left(I^{2}\right)$ adjusted by determining the required information size. The required information size was calculated with an intervention effect of a $10 \%$ relative risk reduction, an overall $5 \%$ risk of a type I error, and a $20 \%$ risk of a type II error. All trial sequential analyses were performed using TSA version 0.9 Beta (www.ctu.dk/tsa/, Copenhagen Trial Unit, Copenhagen, Denmark).

Table 1. Summary of the retrieved trials investigating experimental group and control group.

\begin{tabular}{|c|c|c|c|c|c|}
\hline Author, Year, Country, Reference & RCT & Total $N$ & Treated $(N)$ & Control $(N)$ & QA \\
\hline Buturovic et al., 1998, SI, [29] & No & 30 & $4 \%$ CiT (20) & 1666 U /mL HpR (10) & 3\# \\
\hline Dogra et al., 2002, AU, [30] & Yes & 79 & $26.7 \mathrm{mg} / \mathrm{mL} \mathrm{GM}+1.04 \% \mathrm{CiT}(42)$ & 5000 U /mL HpR (37) & $8^{*}$ \\
\hline Betjes et al., 2004, NL, [31] & No & 58 & $1.35 \% \mathrm{TRD}+4 \% \mathrm{CiT}(37)$ & 5000 U /mL HpR (39) & $3 \#$ \\
\hline Weijmer et al., 2005, NL, [14] & Yes & 291 & $30 \%$ CiT (148) & $5000 \mathrm{U} / \mathrm{mL}$ HpR (143) & $8^{*}$ \\
\hline Nori et al., 2006, USA, [32] & No & 40 & $4 \mathrm{mg} / \mathrm{mL} \mathrm{GM}+3.13 \%$ CiT (41) & $5000 \mathrm{U} / \mathrm{mL} \mathrm{HpR}(21)$ & 3\# \\
\hline Lok et al., 2007, CA, [13] & No & 250 & $4 \%$ CiT (129) & $5000 \mathrm{U} / \mathrm{mL}$ HpR (121) & $3 \#$ \\
\hline MacRae et al., 2008, CA, [12] & No & 61 & $4 \% \mathrm{CiT}(32)$ & $5000 \mathrm{U} / \mathrm{mL}$ HpR (29) & 3\# \\
\hline Power et al., 2009, UK, [4] & Yes & 232 & 46.7\% CiT (132) & $5000 \mathrm{U} / \mathrm{mL} \mathrm{HpR}$ (100) & $8^{*}$ \\
\hline Solomon et al., 2010, UK, [33] & Yes & 107 & $1.35 \%$ TRD $+4 \%$ CiT (53) & $5000 \mathrm{U} / \mathrm{mL} \mathrm{HpR}(54)$ & $8^{*}$ \\
\hline Filiopoulos et al., 2011, GR, [34] & Yes & 117 & 1.35\% TRD + 4\% CiT (119) & 5000 U /mL HpR (58) & $8^{*}$ \\
\hline Maki et al., 2011, USA, [6] & Yes & 407 & 7.0\% CiT + MMP (206) & $5000 \mathrm{U} / \mathrm{mL} \mathrm{HpR}(201)$ & $8^{*}$ \\
\hline Moran et al., 2012, USA, [8] & No & 303 & $320 \mu \mathrm{g} / \mathrm{mL}$ GM + 4\% CiT (155) & $1000 \mathrm{U} / \mathrm{mL} \mathrm{HpR}(148)$ & $3 \#$ \\
\hline Chen et al., 2014, CH, [35] & Yes & 72 & $10 \% \mathrm{NaCl}(36)$ & $3125 \mathrm{U} / \mathrm{mL} \mathrm{HpR}(36)$ & $8^{*}$ \\
\hline
\end{tabular}


Table 1. Cont.

\begin{tabular}{|c|c|c|c|c|c|}
\hline Author, Year, Country, Reference & RCT & Total $N$ & Treated $(N)$ & Control $(N)$ & QA \\
\hline Moghaddas et al., 2015, IR, [18] & Yes & 87 & $\begin{array}{c}10 \mathrm{mg} / \mathrm{mL} \text { TMP } / \mathrm{SMX}+2500 \\
\mathrm{U} / \mathrm{mL} \mathrm{HpR}(46)\end{array}$ & $2500 \mathrm{U} / \mathrm{mL} \mathrm{HpR}(41)$ & $8^{*}$ \\
\hline Kanaa et al., 2015, UK, [17] & Yes & 115 & $4 \%$ EDTA $(59)$ & 5000 U/mL HpR (56) & $8 *$ \\
\hline Zwiech et al., 2016, PL, [21] & Yes & 50 & $4 \%$ CiT (26) & 5000 U /mL HpR (24) & $8^{*}$ \\
\hline Chu et al., 2016, AU, [20] & Yes & 100 & 1000 U/mL HpR (52) & 5000 U/mL HpR (48) & $8^{*}$ \\
\hline Sofroniadou et al., 2017, GR, [23] & Yes & 103 & $\begin{array}{c}70 \% w / w \mathrm{EtOH}+\mathrm{UFH} 2000 \\
\mathrm{U} / \mathrm{mL}(52)\end{array}$ & 2000 U /mL HpR (51) & $8 *$ \\
\hline Winnicki et al., 2018, Au, [24] & No & 406 & $1.35 \% \mathrm{TRD}+4 \% \mathrm{CiT}+\mathrm{HpR}(52)$ & $4 \%$ CiT (54) & $3 \#$ \\
\hline
\end{tabular}

Abbreviations: AU, Australia; Au, Austria; BZ, Brazil; CA, Canada; CH, China; CiT, citrate; EDTA, tetra-sodium ethylenediaminetetraacetic acid; EtOH, ethanol; FR, France; GM, gentamicin; GR, Greece; HpR, heparin; IR, Iran; MMP, $0.15 \%$ methylene blue $+0.15 \%$ methylparaben $+0.015 \%$ propylparaben; $\mathrm{NaCl}$, sodium chloride; $\mathrm{N}$, number; NL, Netherlands; PL, Poland; QA, quality assessment; RCT, randomized controlled trial; SI, Slovenia; TMP/SMX, cotrimoxazole (=trimethoprim/sulfamethoxazole); TRD, taurolidine; UFH, unfractionated heparin; UK, United Kingdom; US, United States. \#, the study was evaluated using Jadad scale. *, the study was assessed using the Newcastle-Ottawa scale.

\section{Results}

\subsection{Eligible Studies}

The literature search yielded 458 potentially eligible articles. By screening the abstracts, we removed 350 irrelevant articles. The remaining 100 articles were assessed further by full-text reading, of which 79 were excluded (Figure 1). Thus, 21 selected articles comparing citrate with heparin lockings for central venous catheters used in hemodialysis were included in this meta-analysis $[4,6,8,12-14,17-24,29-35]$.
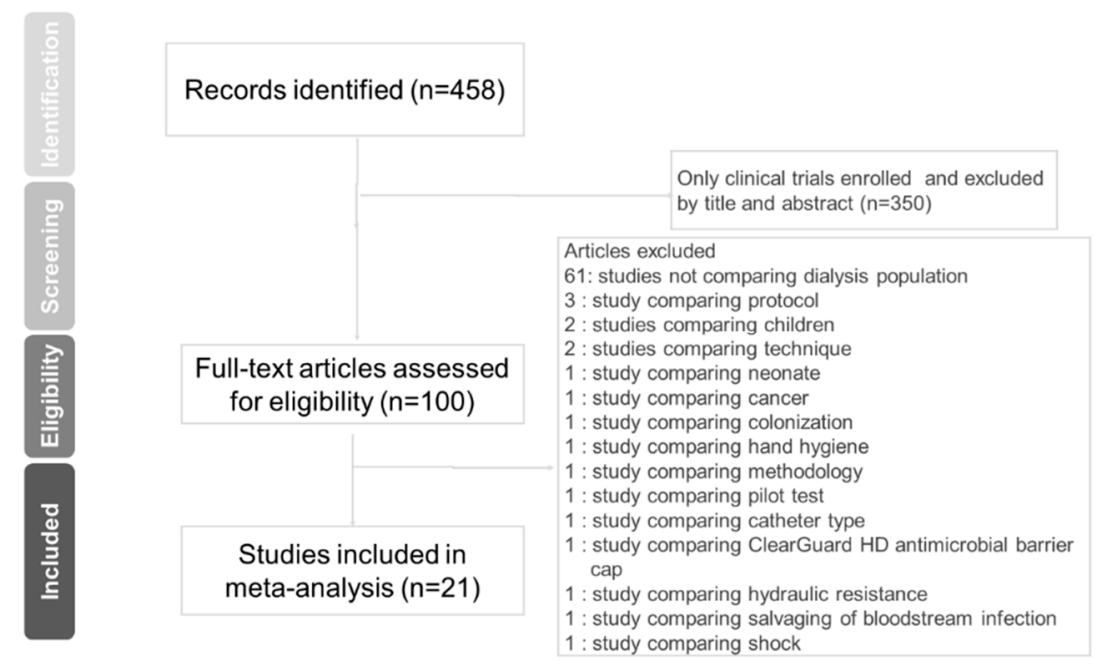

Figure 1. Preferred reporting items for systematic reviews and meta-analyses (PRISMA) flow diagram for the search and identification of the included studies.

The studies published in the selected articles were conducted from the earliest record to July 2018, with a total of 4832 patients and 318,769 total days of catheter use. Six studies compared citrate alone with heparin lockings; 14 studies tested regimens of citrate and other antimicrobials (gentamicin, taurolidine, methylparaben, methylene blue, and propylparaben) with heparin lockings; and two studies compared ethanol or combination solution (citrate, heparin and taurolidine) with non-heparin locking. Studies were conducted in North America (5 studies), South America (1), Europe (12), and Asia (3). A variety of end points were used in these studies. Most studies reported on CRBSI (17 studies [4,6,8,12-14,17,19,21-24,30-34]), followed by ESI (11 studies [4,8,12,14,17-19,24,30,31,33]), 
catheter removal for poor flow (9 studies $[6,8,12,14,18,24,29,31,33]$ ), thrombolytic treatment (8 studies [4,8,14,17,18,32,33]), and mortality (5 studies [6,14,19,32,33]). The characteristics of the studies fulfilling the inclusion criteria are listed in Table 1 . Thirteen studies were identified as RCT, and 6 studies were not double-blinded (Table 1).

\subsection{Pooled Odds for Primary Outcomes and Subgroup Analysis}

\subsubsection{Catheter-Related Bloodstream Infection (CRBSI)}

Seventeen studies (1731 patients; 217,128 catheter days) reported on CRBSI. The incidence of CRBSI was significantly lower in the treated group compared with the control group (OR, $0.424 ; 95 \%$ CI, 0.267-0.673; $p<0.001$ ) (Figure 2). CRBSI subgroup analysis showed that the OR appeared to have a tendency to favor the treatment groups with either the combined regimen (OR, 0.206 ; 95\% $\mathrm{CI}, 0.058-0.730 ; p=0.027)$, the single regimen (OR, $0.289 ; 95 \% \mathrm{CI}, 0.083-0.365 ; p=0.037)$, a regimen containing antibiotics (OR, $0.136 ; 95 \% \mathrm{CI}, 0.051-0.365 ; p=0.002)$, or a low concentration of a major regimen (OR, $0.421 ; 95 \% \mathrm{CI}, 0.186-0.956 ; p=0.039$; Table 2).

\section{Catheter-related bloodstream infection}

\begin{tabular}{lrcr} 
Study name & \multicolumn{3}{c}{ Statistics for each study } \\
\cline { 2 - 4 } & $\begin{array}{r}\text { Odds } \\
\text { ratio }\end{array}$ & $\begin{array}{c}\text { Lower } \\
\text { limit }\end{array}$ & \multicolumn{1}{c}{$\begin{array}{c}\text { Upper } \\
\text { limit }\end{array}$} \\
Dogra 2002) & 0.050 & 0.003 & \multicolumn{1}{l}{0.874} \\
Betjes (2004) & 0.138 & 0.007 & 2.557 \\
Weijmer (2005) & 0.262 & 0.125 & 0.547 \\
Nori (2006) & 0.058 & 0.003 & 1.008 \\
Lok (2007) & 0.136 & 0.048 & 0.388 \\
MacRae (2008) & 0.666 & 0.203 & 2.185 \\
Power (2009) & 0.975 & 0.445 & 2.136 \\
Solomon (2010) & 0.567 & 0.276 & 1.163 \\
Filiopoulos (2011) & 0.368 & 0.162 & 0.837 \\
Maki (2011) & 0.289 & 0.116 & 0.721 \\
Moran (2011) & 0.303 & 0.152 & 0.605 \\
Souweine (2015) & 0.684 & 0.369 & 1.268 \\
Moghaddas (2015) & 0.191 & 0.042 & 0.863 \\
Kanaa (2015) & 0.337 & 0.035 & 3.240 \\
Zwiech (2016) & 32.894 & 1.977 & 547.330 \\
Correa Barcellos (2017) & 1.696 & 0.998 & 2.882 \\
Winnicki (2018) & 0.248 & 0.099 & 0.626 \\
& 0.424 & 0.267 & 0.673
\end{tabular}

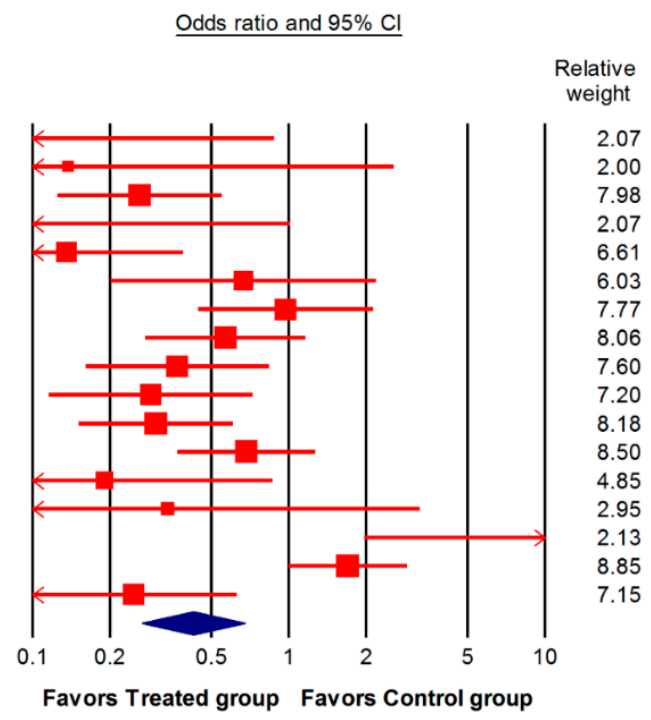

Figure 2. Forest plot of the overall odds ratios for catheter-related bloodstream infection in the treated group versus the control group. The random model of overall odds ratio showed a significant overall effect of interventions in reducing the risk for developing catheter-related bloodstream infections as compared with the control condition (OR, 0.424; 95\% CI, 0.267-0.673; $p<0.001$ ).

\subsubsection{Exit-Site Infection (ESI)}

A total of 11 RCTs (2,425 patients; 231,086 catheter days) described ESI. The incidence of ESI was significantly lower in the treated group compared with the control group (OR, 0.627; 95\% CI, 0.441-0.893; $p=0.001$; Figure 3). Further focusing at exit-site infection (Table 3), the subgroup analysis (combined regimen, regimen containing antibiotic, and concentration of regimen for exit-site infection) disclosed no significant differences between any groups except for combined regimen. 
Table 2. Subgroup analysis of odds ratio based on study designs, combined regimen, regimen containing antibiotic, and concentration of regimen for CRBSI.

\begin{tabular}{ccc}
\hline Subgroup & Odds Ratio & 95\% Confidence Interval \\
\hline \multicolumn{3}{c}{ combined regimen } \\
RCT & 0.606 & $0.298-1.230$ \\
Not RCT & 0.206 & $0.058-0.730$ \\
\hline \multicolumn{3}{c}{ Not combined regimen } \\
RCT & 0.417 & $0.192-0.905$ \\
Not RCT & 0.289 & $0.083-0.365$ \\
\hline \multicolumn{3}{c}{ Regimen containing antibiotic } \\
RCT & 0.191 & $0.023-1.564$ \\
Not RCT & 0.136 & $0.051-0.365$ \\
\hline \multicolumn{3}{c}{ Regimen Not containing antibiotic } \\
RCT & 0.546 & $0.314-0.949$ \\
Not RCT & 0.342 & $0.191-0.614$ \\
\hline \multicolumn{3}{c}{ High Concentration of major regimen } \\
RCT & 0.644 & $0.155-2.671$ \\
\hline \multicolumn{3}{c}{ Low Concentration of major regimen } \\
RCT & 0.421 & $0.186-0.956$ \\
Not RCT & 0.260 & $0.135-0.497$ \\
\hline \multicolumn{2}{c}{ Abbreviation: RCT, randomized controlled trial }
\end{tabular}

Table 3. Subgroup analysis of odds ratio based on study designs, combined regimen, regimen containing antibiotic, and concentration of regimen for exit site infection.

\begin{tabular}{|c|c|c|}
\hline Subgroup & Odds Ratio & 95\% Confidence Interval \\
\hline \multicolumn{3}{|c|}{ combined regimen } \\
\hline $\mathrm{RCT}$ & 0.849 & $0.358-2.011$ \\
\hline Not RCT & 0.706 & $0.307-1.62$ \\
\hline \multicolumn{3}{|c|}{ Not combined regimen } \\
\hline $\mathrm{RCT}$ & 0.503 & $0.276-0.918$ \\
\hline Not RCT & 0.620 & $0.113-3.389$ \\
\hline \multicolumn{3}{|c|}{ Regimen containing antibiotic } \\
\hline RCT & 0.571 & $0.189-1.725$ \\
\hline Not RCT & 0.735 & $0.284-1.905$ \\
\hline \multicolumn{3}{|c|}{ Regimen Not containing antibiotic } \\
\hline RCT & 0.599 & $0.334-1.071$ \\
\hline Not RCT & 0.650 & $0.246-1.722$ \\
\hline \multicolumn{3}{|c|}{ High Concentration of major regimen } \\
\hline RCT & 0.631 & $0.214-1.862$ \\
\hline \multicolumn{3}{|c|}{ Low Concentration of major regimen } \\
\hline RCT & 0.805 & $0.282-2.297$ \\
\hline Not RCT & 0.692 & $0.35-1.368$ \\
\hline
\end{tabular}

Abbreviation: RCT, randomized controlled trial. 


\section{Exit-site infection}

\begin{tabular}{|c|c|c|c|}
\hline \multicolumn{4}{|l|}{ tudy name } \\
\hline & $\begin{array}{l}\text { Odds } \\
\text { ratio }\end{array}$ & $\begin{array}{c}\text { Lower } \\
\text { limit }\end{array}$ & $\begin{array}{c}\text { Upper } \\
\text { limit }\end{array}$ \\
\hline ogra & 0.187 & 0.021 & 678 \\
\hline Betjes (2004) & 0.620 & 0.113 & 3.389 \\
\hline Weijmer (2005) & 0.330 & 0.166 & 655 \\
\hline MacRae (2008) & 0.666 & 0.203 & 2.185 \\
\hline Power (2009) & 1.300 & 0.555 & 3.041 \\
\hline Solomon (2010) & 1.384 & 0.465 & 4.120 \\
\hline Moran (2012) & 0.735 & 0.284 & 1.905 \\
\hline Souweine (2015) & 0.606 & 0.397 & 0.922 \\
\hline Moghaddas (2015) & 0.175 & 0.021 & 1.457 \\
\hline Kanaa (2015) & 0.126 & 0.016 & 1.010 \\
\hline Ninnicki (2018) & 0.882 & 0.395 & 1.971 \\
\hline & 0.627 & 0.441 & 0.893 \\
\hline
\end{tabular}

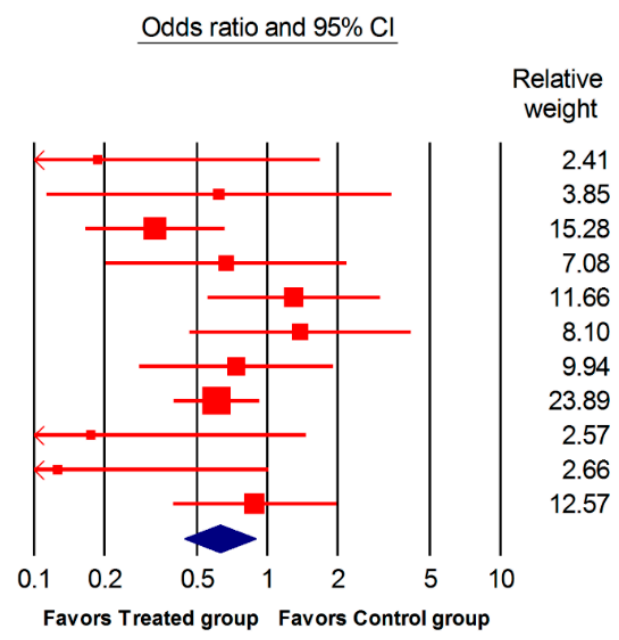

Figure 3. Forest plot of the overall odds ratios for exit-site infection in treated group versus the control group. The random model of overall odds ratio for exit-site infection showed a significant overall effect of interventions in reducing the risk for developing exit-site infection as compared with the control condition (OR, 0.627; 95\% CI, 0.441-0.893; $p=0.001)$.

\subsection{Pooled Odds for Secondary Outcomes and Subgroup Analysis}

\subsubsection{Catheter Withdrawal Due to Malfunction}

Nine studies (1826 patients; 205,163 catheter days) reported catheters being removed for poor blood flow. As shown in Figure 4, no difference was identified between the two groups (OR, 0.696; 95\% CI, 0.397-1.223; $p=0.208$ ). Further subgroup analysis (combined regimen, regimen containing antibiotic, and concentration of regimen for catheter removal due to catheter malfunction) failed to reveal any differences between any groups (Table 4).

\section{The need to remove Catheter for catheter malfunction}

\begin{tabular}{lrrr}
\multicolumn{1}{c}{ Study name } & $\begin{array}{r}\text { Odds } \\
\text { ratio }\end{array}$ & $\begin{array}{c}\text { Lower } \\
\text { limit }\end{array}$ & $\begin{array}{r}\text { Upper } \\
\text { limit }\end{array}$ \\
Buturovic (1998) & 0.450 & 0.028 & 7.224 \\
Betjes (2004) & 0.620 & 0.056 & 6.846 \\
Weijmer (2005) & 0.896 & 0.530 & 1.515 \\
MacRae (2008) & 1.281 & 0.418 & 3.921 \\
Solomon (2010) & 3.165 & 0.839 & 11.934 \\
Maki (2011) & 0.107 & 0.006 & 1.992 \\
Moran (2012) & 0.992 & 0.633 & 1.554 \\
Moghaddas (2015) & 0.191 & 0.066 & 0.555 \\
Winnicki (2018) & 0.187 & 0.040 & 0.879 \\
& 0.696 & 0.397 & 1.223
\end{tabular}

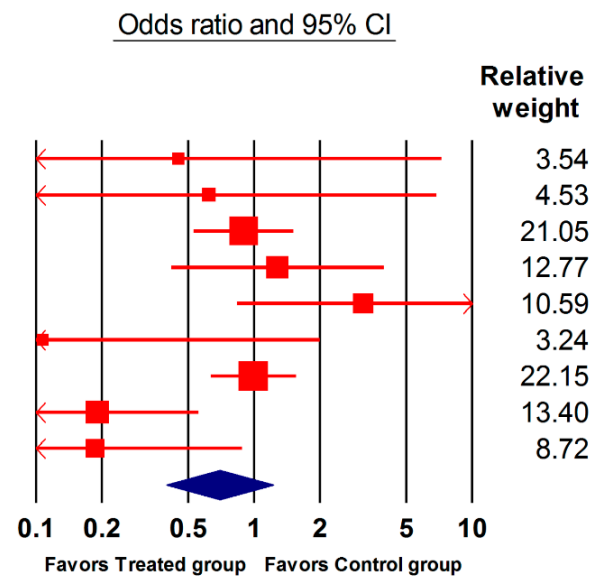

Figure 4. Forest plot of the overall odds ratios for catheter removal due to catheter malfunction in the treated group vs. the control group. The random model of overall odds ratio for the need to remove the catheter for malfunction showed a significant overall effect of the interventions in reducing the risk for catheter removal compared with the control condition (OR, 0.696; 95\% CI, 0.397-1.223; $p=0.208$ ). 
Table 4. Subgroup analysis of odds ratio based on study designs, combined regimen, regimen containing antibiotic, and concentration of regimen for catheter removal due to catheter malfunction.

\begin{tabular}{ccc}
\hline Subgroup & Odds Ratio & \multicolumn{2}{c}{ 95\% Confidence Interval } \\
\hline \multicolumn{3}{c}{ Combined regimen } \\
RCT & 0.520 & $0.086-3.15$ \\
Not RCT & 0.977 & $0.628-1.518$ \\
\hline \multicolumn{3}{c}{ Not combined regimen } \\
RCT & 0.434 & $0.068-2.786$ \\
Not RCT & 1.106 & $0.392-3.124$ \\
\hline \multicolumn{3}{c}{ Regimen containing antibiotic } \\
RCT & 0.741 & $0.087-6.287$ \\
Not RCT & 0.992 & $0.633-1.554$ \\
\hline \multicolumn{3}{c}{ Regimen not containing antibiotic } \\
RCT & 0.329 & $0.051-2.138$ \\
Not RCT & 1.010 & $0.39-2.619$ \\
\hline \multicolumn{3}{c}{ High concentration of major regimen } \\
RCT & 0.896 & $0.029-27.554$ \\
\hline \multicolumn{3}{c}{ Low concentration of major regimen } \\
Not RCT & 0.479 & $0.051-4.537$ \\
\multicolumn{2}{c}{0.995} & $0.663-1.494$ \\
\hline
\end{tabular}

\subsubsection{Thrombolytic Treatment Due to Catheter Malfunction}

Overall, in eight RCTs (2092 patients; 220,460 catheter days) included in this meta-analysis the patients underwent thrombolytic treatment $[4,8,14,17,18,32,33]$. The incidence of thrombolytic treatment was not significantly lower in the treated group compared with the control group using the random-effects model (OR, 1.105; 95\% CI, 0.655-1.573; $p=0.946$; Figure 5). Thrombolytic treatment subgroup analysis showed no differences in the OR between the two groups (Table 5).

The need to receive thrombolytic treatment for catheter malfunction

\begin{tabular}{lrrr}
\multicolumn{1}{c}{ Study name } & & & \\
& $\begin{array}{r}\text { Odds } \\
\text { ratio }\end{array}$ & $\begin{array}{c}\text { Lower } \\
\text { limit }\end{array}$ & $\begin{array}{c}\text { Upper } \\
\text { limit }\end{array}$ \\
Weijmer (2005) & 1.055 & 0.749 & 1.486 \\
Nori (2006) & 0.345 & 0.108 & 1.102 \\
Lok (2007) & 0.599 & 0.431 & 0.833 \\
Power (2009) & 1.867 & 1.413 & 2.466 \\
Solomon (2010) & 2.480 & 1.683 & 3.656 \\
Moran (2012) & 0.687 & 0.522 & 0.904 \\
Moghaddas (2015) & 0.263 & 0.029 & 2.354 \\
Kanaa (2015) & 1.310 & 0.837 & 2.052 \\
& 1.015 & 0.655 & 1.573
\end{tabular}

Odds ratio and $95 \% \mathrm{Cl}$

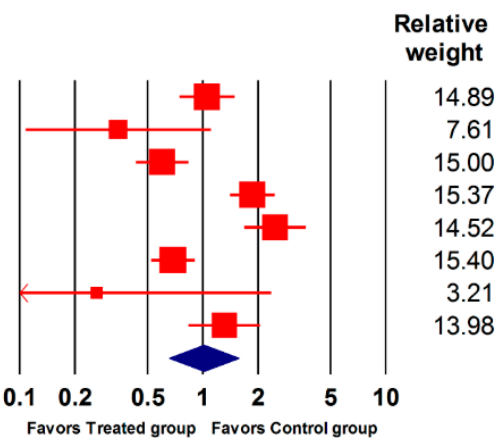

Figure 5. Forest plot of the overall odds ratios for thrombolytic treatments for catheter malfunction in the treated group versus the control group. The random model of overall odds ratio for the need to administer thrombolytic treatment for catheter malfunction showed a significant overall reduced risk for receiving thrombolytic treatments with interventions as compared with the control condition (OR, 1.105; 95\% CI, 0.655-1.573; $p=0.946)$. 
Table 5. Subgroup analysis of odds ratio based on study designs, combined regimen, regimen containing antibiotic, and concentration of regimen for the need of thrombolytic treatment for catheter malfunction.

\begin{tabular}{|c|c|c|}
\hline Subgroup & Odds Ratio & $95 \%$ Confidence Interval \\
\hline \multicolumn{3}{|c|}{ Combined regimen } \\
\hline $\mathrm{RCT}$ & 2.480 & $1.214-5.066$ \\
\hline Not RCT & 0.620 & $0.382-1.004$ \\
\hline \multicolumn{3}{|c|}{ Not combined regimen } \\
\hline $\mathrm{RCT}$ & 1.320 & $0.888-1.961$ \\
\hline Not RCT & 0.599 & $0.344-1.043$ \\
\hline \multicolumn{3}{|c|}{ Regimen containing antibiotic } \\
\hline RCT & 1.969 & $0.944-4.107$ \\
\hline Not RCT & 0.620 & $0.382-1.004$ \\
\hline \multicolumn{3}{|c|}{ Regimen not containing antibiotic } \\
\hline $\mathrm{RCT}$ & 1.385 & $0.893-2.149$ \\
\hline Not RCT & 0.345 & $0.108-1.102$ \\
\hline \multicolumn{3}{|c|}{ High concentration of major regimen } \\
\hline $\mathrm{RCT}$ & 1.415 & $0.784-2.554$ \\
\hline \multicolumn{3}{|c|}{ Low concentration of major regimen } \\
\hline $\mathrm{RCT}$ & 2.480 & $1.042-5.902$ \\
\hline Not RCT & 0.637 & $0.518-0.783$ \\
\hline
\end{tabular}

\subsubsection{All-Cause Mortality}

The meta-analysis included five RCTs (2,327 patients) comparing all-cause mortality rate between the two groups; no significant difference was identified (OR, 0.909; 95\% CI, 0.580-1.423; $p=0.676$; Figure 6). The corresponding subgroup analysis (combined regimen, regimen containing antibiotic, and concentration of regimen for all-cause mortality) showed no apparent differences between the two groups (Table 6).

\section{All-cause mortality}

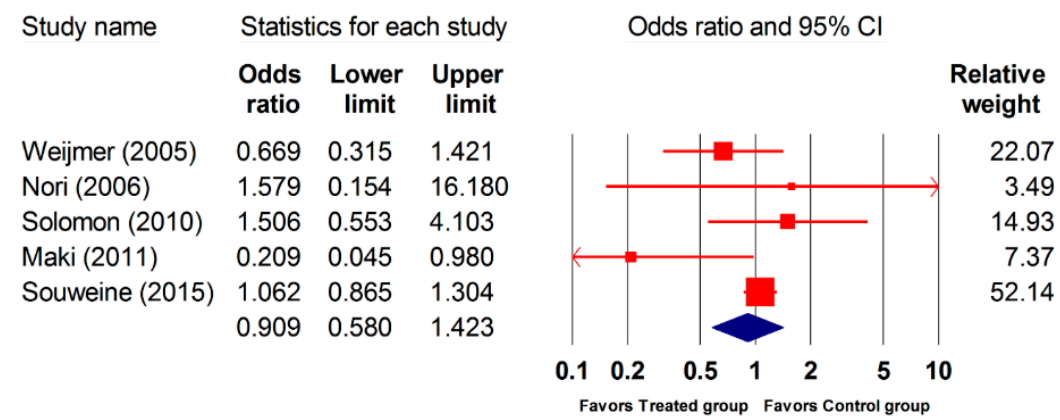

Figure 6. Forest plot of the overall odds ratios for all-cause mortality in the treated group versus the control group. The random model of overall odds ratio for all-cause mortality rate showed a significant overall effect of the interventions in reducing mortality rate as compared with the control condition (OR, 0.909; 95\% CI, 0.580-1.423; $p=0.676$ ). 
Table 6. Subgroup analysis of odds ratio based on study designs, combined regimen, regimen containing antibiotic, and concentration of regimen for all-cause mortality.

\begin{tabular}{ccc}
\hline Subgroup & Odds Ratio & 95\% Confidence Interval \\
\hline \multicolumn{3}{c}{ Combined regimen } \\
RCT & 0.725 & $0.237-2.211$ \\
Not RCT & 1.579 & $0.154-16.18$ \\
\hline \multicolumn{3}{c}{ Not combined regimen } \\
RCT & 0.884 & $0.404-1.933$ \\
\hline \multicolumn{3}{c}{ Regimen containing antibiotic } \\
RCT & 1.506 & $0.388-5.838$ \\
Not RCT & 1.579 & $0.154-16.18$ \\
\hline \multicolumn{3}{c}{ Regimen not containing antibiotic } \\
RCT & 0.723 & $0.367-1.425$ \\
\hline & High concentration of major regimen \\
RCT & 0.669 & $0.054-8.324$ \\
\hline & Low Concentration of major regimen \\
RCT & 0.615 & $0.09-4.22$ \\
Not RCT & 1.579 & $0.154-16.18$ \\
\hline
\end{tabular}

Abbreviation: RCT, randomized controlled trial.

\subsection{Pooled Odds for Outcomes in Trial Sequential Analysis}

In trial sequential analysis between the treated and control groups, the overall OR of CRBSI was 0.439 (95\% CI, $0.290-0.668 ; p<0.001$; Figure 7a), the OR of ESI was 0.644 (95\% CI, $0.469-0.883 ; p=0.006$; Figure $7 \mathrm{~b})$, the OR of the need to remove the catheter for catheter malfunction was $0.746(95 \% \mathrm{CI}$, 0.431-1.293; $p=0.151$; Figure 7c), the OR of the need to receive thrombolytic treatment for catheter malfunction was 1.015 (95\% CI, 0.655-1.573; $p=0.461$; Figure $7 \mathrm{~d})$, and the OR of all-cause mortality was 0.976 (95\% CI, 0.663-1.439; $p=0.296$; Figure 7e).

(a) Trial sequential analysis of catheter-related bloodstream infection

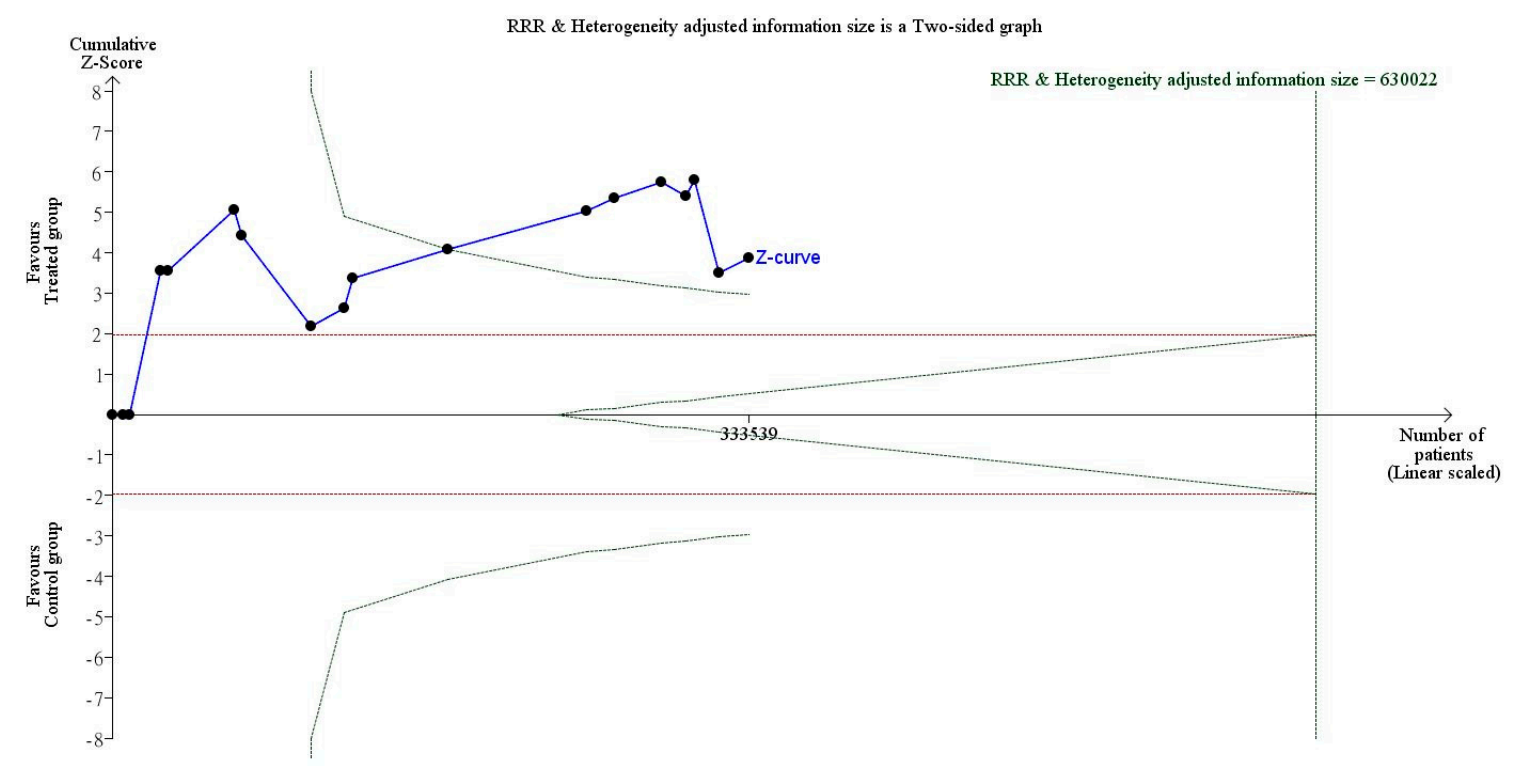

Figure 7. Cont. 
(b) Trial sequential analysis of exit-site infection

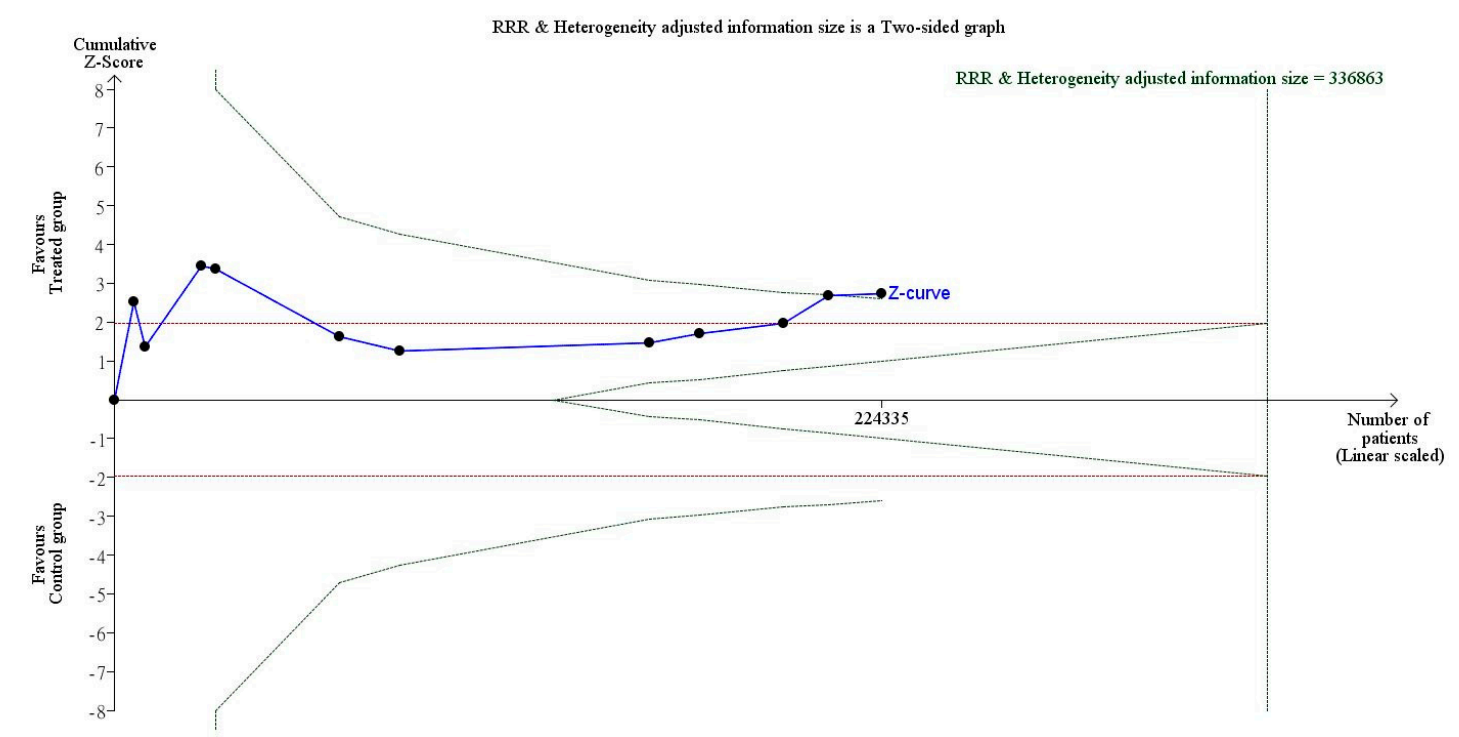

(c) Trial sequential analysis of catheter removal for catheter malfunction

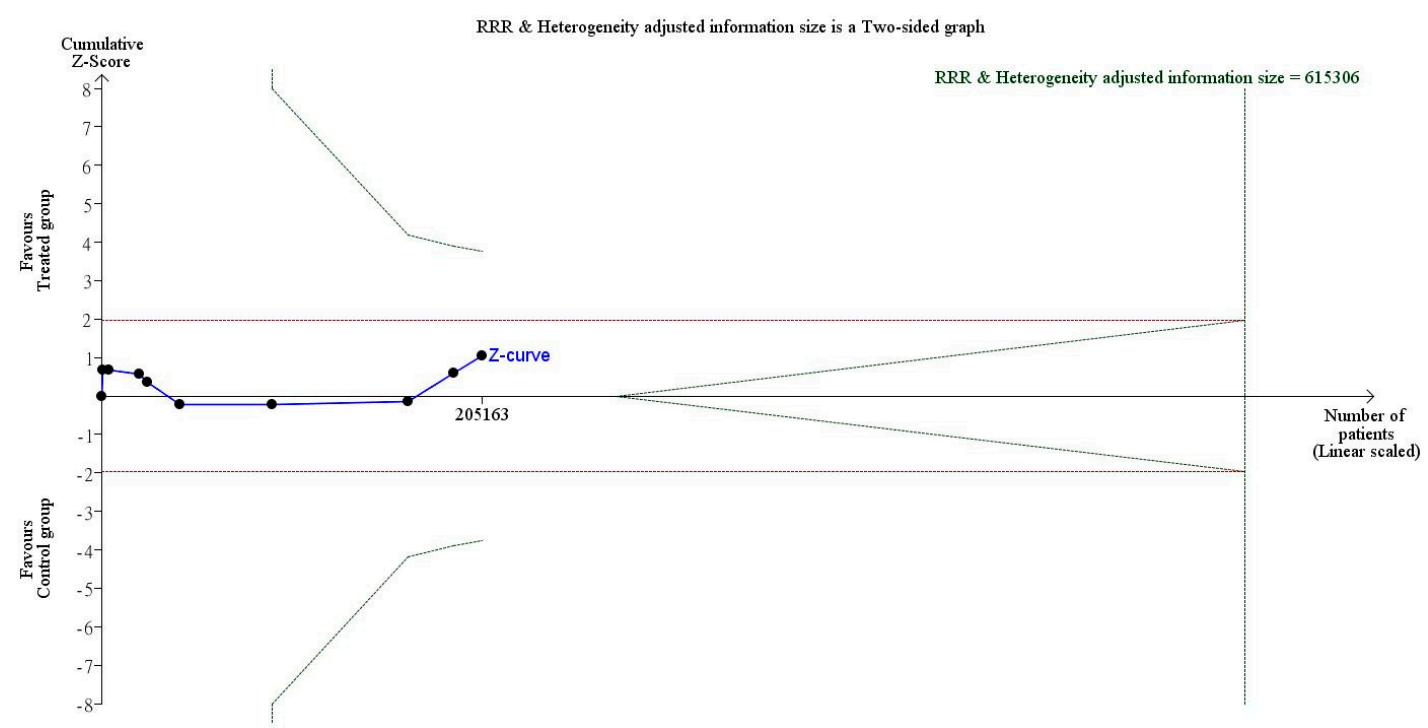

(d) Trial sequential analysis of thrombolytic treatments for catheter malfunction

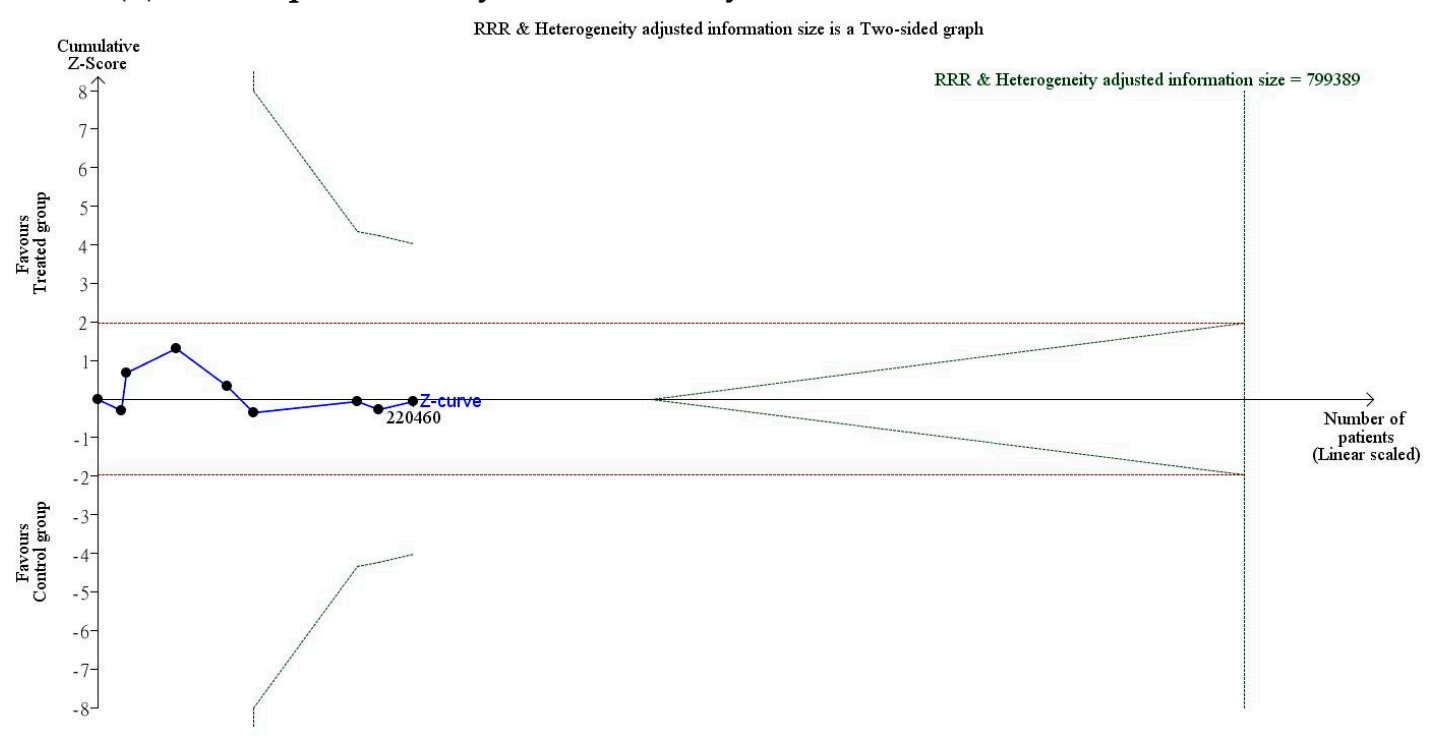

Figure 7. Cont. 
(e) Trial sequential analysis of all-cause mortality

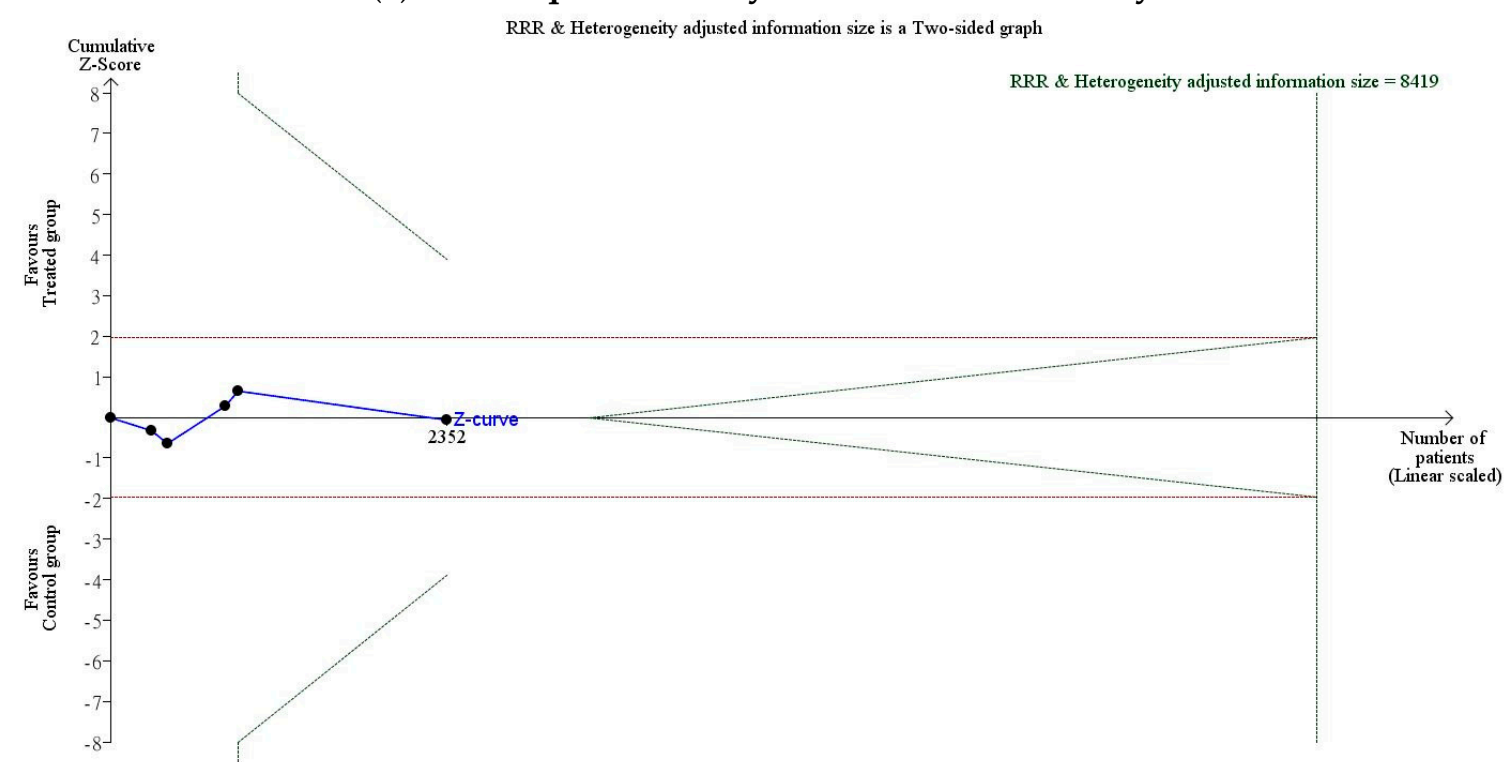

Figure 7. Trial sequential analysis of the odds ratio for evaluation event: (a) Trial sequential analysis of catheter-related bloodstream infection. Trial sequential analysis of 17 studies with a lower risk of bias in reporting catheter-related bloodstream infection, with a control event proportion of $17 \%$, diversity of $45 \%$, type I error of $5 \%$, power of $80 \%$, and relative risk reduction of $30 \%$. The required information size of 630,022 was not reached and none of the boundaries for benefit, harm, or futility were crossed, leaving the meta-analysis inconclusive at a $30 \%$ relative risk reduction. The overall OR of CRBSI was 0.439 (95\% CI, 0.290-1.668; $p<0.001$ ); (b) trial sequential analysis of exit-site infection. Trial sequential analysis of eleven studies with low risk of bias reporting exit-site infection, with a control event proportion of $17 \%$, diversity of $30 \%$, type I error of $5 \%$, power of $80 \%$, and relative risk reduction of $30 \%$. The required information size of 336,863 was not reached and none of the boundaries for benefit, harm, or futility were crossed, leaving the meta-analysis inconclusive at a $30 \%$ relative risk reduction. The OR of ESI was 0.644 (95\% CI, 0.469-0.883; $p=0.006)$; (c) trial sequential analysis of nine studies with a lower risk of bias reporting the need to remove the catheter for catheter malfunction, with a control event proportion of $17 \%$, diversity of $71 \%$, type I error of $5 \%$, power of $80 \%$, and relative risk reduction of $30 \%$. The required information size of 625,306 were not reached and none of the boundaries for benefit, harm, or futility were crossed, leaving the meta-analysis inconclusive at a $30 \%$ relative risk reduction. The OR of the need to remove the catheter for catheter malfunction was 0.746 (95\% CI, 0.431-1.293; $p=0.151$ ); (d) trial sequential analysis of thrombolytic treatments for catheter malfunction. Trial sequential analysis of nine studies with low risk of bias reporting the need to receive thrombolytic treatment for catheter malfunction, with a control event proportion of $17 \%$, diversity of $91 \%$, type I error of $5 \%$, power of $80 \%$, and relative risk reduction of $30 \%$. The required information size of 615,306 were not reached and none of the boundaries for benefit, harm, or futility were crossed, leaving the meta-analysis inconclusive at a $30 \%$ relative risk reduction. The OR of the need to receive thrombolytic treatment for catheter malfunction was 1.015 (95\% CI, 0.655-1.573; $p=0.461)$; (e) trial sequential analysis of all-cause mortality. Trial sequential analysis of five studies with a lower risk of bias reporting all-cause mortality, with a control event proportion of $17 \%$, diversity of $78 \%$, type I error of $5 \%$, power of $80 \%$, and relative risk reduction of $30 \%$. The required information size of 8419 were not reached and none of the boundaries for benefit, harm, or futility were crossed, leaving the meta-analysis inconclusive at a $30 \%$ relative risk reduction. The OR of all-cause mortality was 0.976 (95\% CI, 0.663-1.439; $p=0.296$ ). Notes: The solid blue line is the cumulative Z-curve. The vertical black dashed line is required information size. The green dashed lines represent the trial sequential monitoring boundaries and the futility boundaries. 


\subsection{Funnel Plot for the Overall OR of the Included Studies among Four Outcomes}

We examined possible sources of underlying heterogeneity across studies. With regards to OR heterogeneity, the $I^{2}$ value was calculated in both the overall studies included. In the funnel plot of the OR for evaluation event, the $I^{2}$ value of CRBSI was $70.1 \%(p=0.303$, Figure $8 \mathrm{a})$, ESI was $28.0 \%$ $(p=0.010$; Figure $8 b)$, the need to remove the catheter for catheter malfunction was $55.9 \%(p=0.208$; Figure $8 c)$, the need to receive thrombolytic treatment for catheter malfunction was $88.69 \%(p=0.946$; Figure $8 \mathrm{~d})$, and all-cause mortality was $88.6 \%$ ( $p=0.804$; Figure $8 \mathrm{e})$.

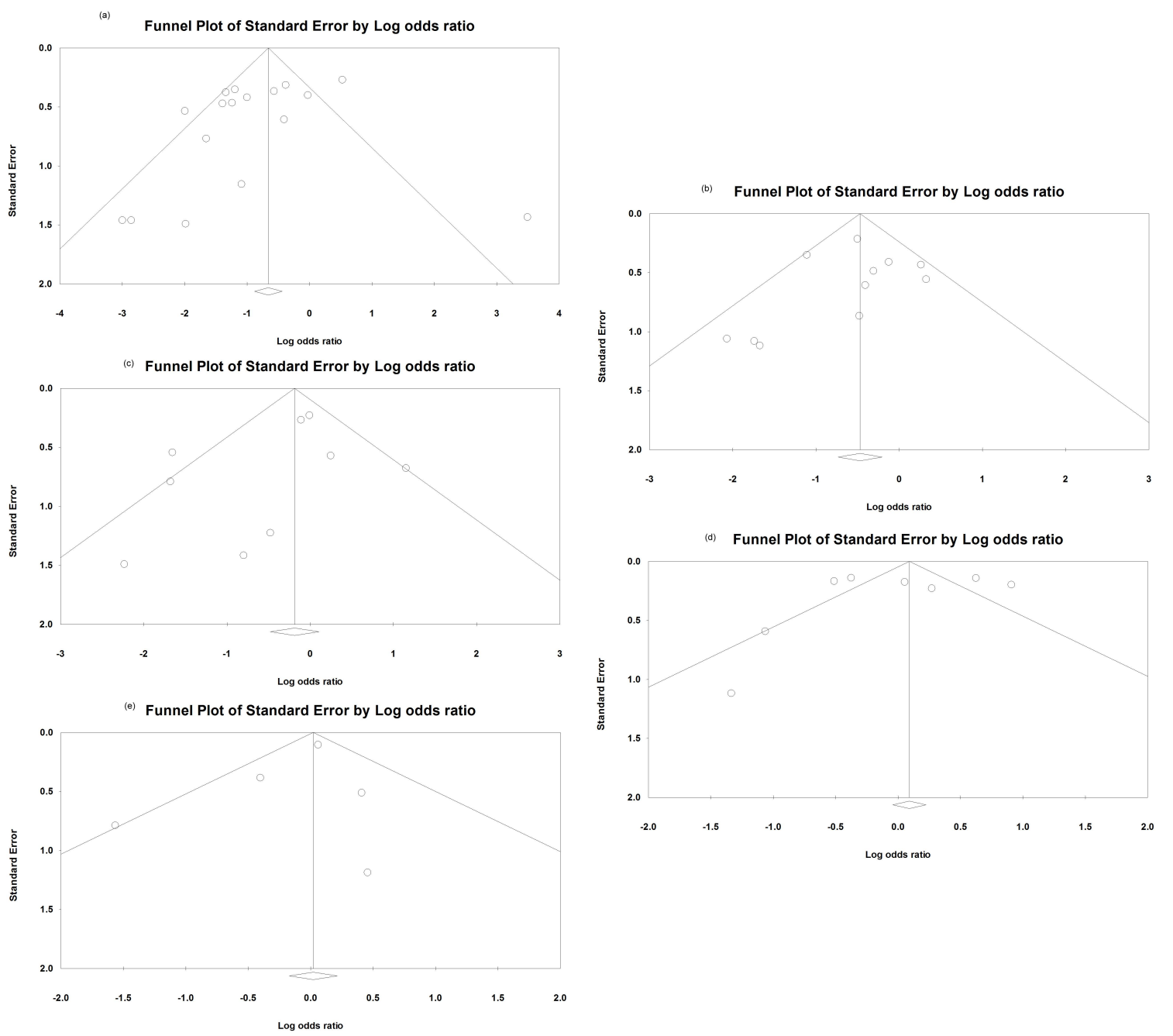

Figure 8. Funnel plot of the odds ratio for evaluation event: (a) Funnel plot of the odds ratio of catheter-related bloodstream infection. $I^{2}$ value, $70.1 \% ; p=0.303$; (b) funnel plot of the odds ratio of exit-site infection. $I^{2}$ value, $28.0 \% ; p=0.010$; (c) funnel plot of the odds ratio of catheter removal for catheter malfunction. $I^{2}$ value, $55.9 \% ; p=0.208$; (d) funnel plot of the odds ratio of thrombolytic treatments for catheter malfunction. $I^{2}$ value, $88.69 \% ; p=0.946$; (e) funnel plot of the odds ratio of all-cause mortality. $I^{2}$ value, $88.6 \% ; p=0.804$. Regarding odds ratio heterogeneity, the $I^{2}$ value in both the overall studies included is indicated for each case. Egger's test revealed the existence of significant publication bias regarding the overall odds ratios, $p$-value is indicated for each case.

\section{Discussion}

Our meta-analysis and trial sequential analysis shows that routine locking solutions for hemodialysis catheters could effectively reduce the incidence of CRBSI and ESI. Our current meta-analysis, based on 21 selected studies with a total of 6118 participants, showed that the incidence of CRBSI and ESI significantly decreased in the treated group relative to the control group, 
that is less infections when using citrate or citrate mixtures versus heparin. Moreover, we found no significant difference in preserving catheter function, including in the need for catheter withdrawal or for thrombolytic treatment due to catheter malfunction, between the treated and control groups. We found no significant alteration in all-cause mortality between the two groups. The lack of statistical significance may not only be due to the heterogeneity and underlying variance in the outcomes of each regimen, but also due to inadequate required information sizes, as revealed by the trial sequential analysis. Regular locking care with citrate is standard practice for patients undergoing hemodialysis in many healthcare institutes, but not in some countries including Taiwan. Our updated review suggests that the role of routine locking solutions in preventing CRBSI and ESI in hemodialysis patients is robust. However, it does not show a benefit in preserving catheter function in hemodialysis patients, including in the need to remove catheters or in the need for thrombolytic treatment for catheter malfunction.

The current study shows that the incidence of CRBSI significantly decreased in the treated group relative to the control group, which is consistent with previous studies [36,37]. Subgroup analyses based on the type of locking solutions for hemodialysis catheters revealed that the usage of citrate-base regimens was associated with a lower incidence of CRBSI [4,14]. Our subgroup analysis for the concentration of citrate used showed that the incidence of CRBSI was similar in treated group, although the American Society of Diagnostic and Interventional Nephrology and the European Renal Best Practice recommend $4 \%$ citrate to be used as a catheter locking solution [38,39]. In some countries, including Taiwan, $4 \%$ citrate is still not routinely used in locking solutions for hemodialysis catheters. The current meta-analysis emphasizes that $4 \%$ citrate shows a benefit and could be routinely used as a locking solution for hemodialysis catheters.

Our current study shows that the incidence of ESI is significantly decreased in the treated group compared with the control group. Our result is in agreement with previous studies $[14,19]$. In some studies, patients received additional antibiotic ointments at the exit site during dressing changes, which could reduce the incidence of ESI $[8,14,40]$. After subgroup categorization, there is no significant difference between two groups except for combined regimen, which could result from the heterogeneity of the included studies and inadequate information size.

We found no significant difference in preserving catheter function between the treated and control groups, including the need to remove catheters or the need for thrombolytic treatment. However, Yahav et al. reported that citrate reduced catheter removals [41]. This incongruity may arise from the following: (1) Variation in enrollment criteria and definitions for the spectrum of catheter removal and (2) the number of cases is still limited because the meta-analysis information size does not meet the required information size. Concerning thrombolytic treatments and thrombosis episodes, our report is similar to previous studies [41,42]. Focusing on the need to remove catheters and to receive thrombolytic treatment for catheter malfunction, further large-scale RCTs are necessary to elucidate this issue for preserving catheter function.

The possible association between the two groups and all-cause mortality was not statistically significant in the current study (OR, $0.909 ; 95 \%$ CI, $0.580-1.423 ; p=0.676)$. Subgroup analysis showed no difference in all-cause mortality. Mortality due to CRBSIs or ESIs account around one-tenth of all hemodialysis patient deaths [1-4]. Protective strategies with locking solutions to prevent CRBSIs and ESIs in hemodialysis patients still cannot decrease the mortality rate. Further large-scale RCTs are necessary to elucidate modifiable risk factor for decreasing morality in hemodialysis patients.

Guidelines for the Prevention of Intravascular Catheter-Related Infections has been published by the Center for Disease Control and Prevention [15], which recommends using prophylactic antimicrobial locking solution in patients undergoing hemodialysis who have a history of multiple CRBSI, despite optimal maximal adherence to aseptic techniques (Category II). This recommendation has been embraced by some dialysis centers due to the low execution rate of locking solutions in preventing CRBSI in hemodialysis patients. In fact, many challenges persist in managing daily care in dialysis centers, such as a lack of safety locking solutions for hemodialysis catheters, lack of a designated health-care workers to perform locking care, limited training on catheter care among 
health-care workers of dialysis centers, potential hemodialysis patients' noncompliance due to discomfort, as well as health-care workers being unable to maintain high adherence rates in conducting care procedures.

The current study has several limitations. Firstly, the enrolled trials and studies included in the primary analysis dealt with different indications for outcome measures by randomizing a variety of patient groups in different clinical settings. Thus, there is the risk of introducing potentially heterogeneity. Additionally, it is difficult to perform a subgroup analysis based on conditions, such as catheter type, heparin dosage, and other differences in individual unit practices. Secondly, differences in the study individuals, disease severity, setting, and type of infections between individual studies made the study population highly heterogeneous. The $I^{2}$ value for OR heterogeneity ranged from $25 \%$ to $50 \%$, and this heterogeneity would impact the findings of this meta-analysis. Thus, the influence of measurement precision was considered when reporting treatment effectiveness using ORs. Due to the lack of adjusted data in our selected trials, we compiled the unadjusted ORs. We therefore suggest that future similar trials should record serial changes in catheter function and infection status to provide a more accurate indication of clinical effectiveness. Regardless of aforementioned limitations, we have minimized bias throughout the process by our methods of study identification, data selection, and statistical analysis, as well as in our control of publication bias. These steps should strengthen the stability and accuracy of the meta-analysis. Our findings of this meta-analysis are reliable to provide suggestions for improving clinical care.

\section{Conclusions}

In conclusion, our study demonstrated that routine locking solutions for hemodialysis catheters could effectively reduce the incidence of CRBSI and ESI. Our findings showed no benefit of routine locking solutions for hemodialysis catheters in decreasing all-cause mortality as well as preserving catheter function, including in the need to remove catheters and in the need to receive thrombolytic treatment, both due to catheter malfunction. The latter results lack statistical significance and the comparisons are limited due to the heterogeneity of the included trials and inadequate information size. Therefore, further well-conducted observational studies and randomized controlled trials are urgently needed to conclusively evaluate the impact of routine locking solutions on preserving catheter function and improving the rates of all-cause mortality.

Supplementary Materials: The following are available online at http:/ /www.mdpi.com/2077-0383/8/3/412/s1, Table S1: PRISMA 2009 Checklist.

Author Contributions: Conceptualization, C.-H.C., Y.-M.C., Y.Y., Y.-J.C., L.-J.Y. and H.-C.Y.; Methodology, C.-H.C., Y.-M.C. and Y.-J.C.; Software, C.-H.C., Y.-M.C. and Y.-J.C.; Validation, C.-H.C., Y.-M.C., Y.Y. and Y.-J.C.; Formal Analysis, C.-H.C., Y.-M.C. and Y.-J.C.; Investigation, X.X.; Data Curation, C.-H.C.; Writing-Original Draft Preparation, C.-H.C.; Writing-Review and Editing, C.-H.C., Y.-M.C., Y.Y. and Y.-J.C.; Writing-Approval, C.-H.C., Y.-M.C., Y.Y., Y.-J.C., L.-J.Y. and H.-C.Y.; Visualization, C.-H.C. and Y.-M.C.; Project Administration, C.-H.C.; Funding Acquisition, C.-H.C.

Funding: The present work was partially supported by a grant obtained from the Changhua Christian Hospital (106-CCHIRP-097).

Acknowledgments: The authors thank Ping-Tao Tseng for technical analysis. The authors thank the staff at the Epidemiology and Biostatistics Center, the Department of Pharmacology, and the Department of Computer at Changhua Christian Hospital for the literature findings. This research project would not have been possible without the support of many people. The authors wish to express their gratitude to the staffs of the Department of Critical Care, Epidemiology and Biostatistics Center, the Division of Nephrology, the Division of Infectious Diseases, the Department of Pharmacology, the Department of Nursing, and the Department of Healthcare Quality at Changhua Christian Hospital who were extremely helpful and provided invaluable assistance and support.

Conflicts of Interest: All authors declare that they have no competing interests. The sponsors had no role in the design, execution, interpretation, or writing of the study. 


\section{Appendix A}

Supplement Search strategy in PubMed

$\# 1$ lock

\#2 filling solution

\#3 \#1 or \#2

\#4 End-Stage Kidney Disease or Disease, End-Stage Kidney, End Stage Kidney Disease, End-Stage Chronic Kidney Failure, End-Stage Renal Disease, End-Stage Renal Disease, Chronic Chronic Renal Failure, or ESRD

\#5 Renal Dialyses, Renal Dialysis, Hemodialyses, Extracorporeal Dialysis or Renal replacement therapy \#6 Catheter Related Infections, Catheter-Related Infection

\#7 \#4 or \#5 and \#6

$\# 8 \# 3$ and \#7

\section{References}

1. Liu, K.D.; Chertow, G.M. Dialysis in the Treatment of Renal Failure. In Harrison's Principles of Internal Medicine, 20e; Jameson, J.L., Fauci, A.S., Kasper, D.L., Hauser, S.L., Longo, D.L., Loscalzo, J., Eds.; McGraw-Hill Education: New York, NY, USA, 2018.

2. Schwab, S.J.; Beathard, G. The hemodialysis catheter conundrum: Hate living with them, but can't live without them. Kidney Int. 1999, 56, 1-17. [CrossRef] [PubMed]

3. Zhao, Y.; Li, Z.; Zhang, L.; Yang, J.; Yang, Y.; Tang, Y.; Fu, P. Citrate versus heparin locking for hemodialysis catheters: A systematic review and meta-analysis of randomized controlled trials. Am. J. Kidney Dis. 2014, 63, 479-490. [CrossRef] [PubMed]

4. Power, A.; Duncan, N.; Singh, S.K.; Brown, W.; Dalby, E.; Edwards, C.; Lynch, K.; Prout, V.; Cairns, T.; Griffith, M.; et al. Sodium citrate versus heparin catheter lockings for cuffed central venous catheters: A single-center randomized controlled trial. Am. J. Kidney Dis. 2009, 53, 1034-1041. [CrossRef] [PubMed]

5. Allon, M. Current management of vascular access. Clin. J. Am. Soc. Nephrol. 2007, 2, 786-800. [CrossRef]

6. Maki, D.G.; Ash, S.R.; Winger, R.K.; Lavin, P.; Investigators, A.T. A novel antimicrobial and antithrombotic locking solution for hemodialysis catheters: A multi-center, controlled, randomized trial. Crit. Care Med. 2011, 39, 613-620. [CrossRef] [PubMed]

7. Yevzlin, A.S.; Sanchez, R.J.; Hiatt, J.G.; Washington, M.H.; Wakeen, M.; Hofmann, R.M.; Becker, Y.T. Concentrated heparin locking is associated with major bleeding complications after tunneled hemodialysis catheter placement. In Seminars in Dialysis; Blackwell Publishing Ltd.: Oxford, UK, 2007; Volume 20, pp. 351-354.

8. Moran, J.; Sun, S.; Khababa, I.; Pedan, A.; Doss, S.; Schiller, B. A randomized trial comparing gentamicin/citrate and heparin lockings for central venous catheters in maintenance hemodialysis patients. Am. J. Kidney Dis. 2012, 59, 102-107. [CrossRef]

9. Shanks, R.M.; Donegan, N.P.; Graber, M.L.; Buckingham, S.E.; Zegans, M.E.; Cheung, A.L.; O'Toole, G.A. Heparin stimulates Staphylococcus aureus biofilm formation. Infect. Immun. 2005, 73, 4596-4606. [CrossRef]

10. Shanks, R.M.; Sargent, J.L.; Martinez, R.M.; Graber, M.L.; O’Toole, G.A. Catheter locking solutions influence staphylococcal biofilm formation on abiotic surfaces. Nephrol. Dial. Transplant. 2006, 21, 2247-2255. [CrossRef]

11. Ibberson, C.B.; Parlet, C.P.; Kwiecinski, J.; Crosby, H.A.; Meyerholz, D.K.; Horswill, A.R. Hyaluronan Modulation Impacts Staphylococcus aureus Biofilm Infection. Infect. Immun. 2016, 84, 1917-1929. [CrossRef] [PubMed]

12. Macrae, J.M.; Dojcinovic, I.; Djurdjev, O.; Jung, B.; Shalansky, S.; Levin, A.; Kiaii, M. Citrate 4\% versus heparin and the reduction of thrombosis study (CHARTS). Clin. J. Am. Soc. Nephrol. 2008, 3, 369-374. [CrossRef]

13. Lok, C.E.; Appleton, D.; Bhola, C.; Khoo, B.; Richardson, R.M. Trisodium citrate $4 \%-$ An alternative to heparin capping of haemodialysis catheters. Nephrol. Dial. Transplant. 2007, 22, 477-483. [CrossRef] [PubMed] 
14. Weijmer, M.C.; van den Dorpel, M.A.; Van de Ven, P.J.; ter Wee, P.M.; van Geelen, J.A.; Groeneveld, J.O.; van Jaarsveld, B.C.; Koopmans, M.G.; le Poole, C.Y.; Schrander-Van der Meer, A.M.; et al. Randomized, clinical trial comparison of trisodium citrate $30 \%$ and heparin as catheter-lockinging solution in hemodialysis patients. J. Am. Soc. Nephrol. 2005, 16, 2769-2777. [CrossRef]

15. O'grady, N.P.; Alexander, M.; Burns, L.A.; Dellinger, E.P.; Garland, J.; Heard, S.O.; Lipsett, P.A.; Masur, H.; Mermel, L.A.; Pearson, M.L. Guidelines for the prevention of intravascular catheter-related infections. Clin. Infect. Dis. 2011, 52, e162-e193. [CrossRef] [PubMed]

16. Thorlund, K.; Imberger, G.; Walsh, M.; Chu, R.; Gluud, C.; Wetterslev, J.; Guyatt, G.; Devereaux, P.J.; Thabane, $\mathrm{L}$. The number of patients and events required to limit the risk of overestimation of intervention effects in meta-analysis-A simulation study. PLoS ONE 2011, 6, e25491. [CrossRef] [PubMed]

17. Kanaa, M.; Wright, M.J.; Akbani, H.; Laboi, P.; Bhandari, S.; Sandoe, J.A. Cathasept Line Locking and Microbial Colonization of Tunneled Hemodialysis Catheters: A Multicenter Randomized Controlled Trial. Am. J. Kidney Dis. 2015, 66, 1015-1023. [CrossRef] [PubMed]

18. Moghaddas, A.; Abbasi, M.R.; Gharekhani, A.; Dashti-Khavidaki, S.; Razeghi, E.; Jafari, A.; Khalili, H. Prevention of hemodialysis catheter-related blood stream infections using a cotrimoxazole-locking technique. Future Microbiol. 2015, 10, 169-178. [CrossRef]

19. Souweine, B.; Lautrette, A.; Gruson, D.; Canet, E.; Klouche, K.; Argaud, L.; Bohe, J.; Garrouste-Orgeas, M.; Mariat, C.; Vincent, F.; et al. Ethanol locking and risk of hemodialysis catheter infection in critically ill patients. A randomized controlled trial. Am. J. Respir. Crit. Care Med. 2015, 191, 1024-1032. [CrossRef]

20. Chu, G.; Fogarty, G.M.; Avis, L.F.; Bergin, S.; McElduff, P.; Gillies, A.H.; Choi, P. Low dose heparin locking $(1000 \mathrm{U} / \mathrm{mL})$ maintains tunnelled hemodialysis catheter patency when compared with high dose heparin (5000 U/mL): A randomised controlled trial. Hemodial. Int. 2016, 20, 385-391. [CrossRef]

21. Zwiech, R.; Adelt, M.; Chrul, S. A Taurolidine-Citrate-Heparin Locking Solution Effectively Eradicates Pathogens from the Catheter Biofilm in Hemodialysis Patients. Am. J. Ther. 2016, 23, e363-e368. [CrossRef]

22. Correa Barcellos, F.; Pereira Nunes, B.; Jorge Valle, L.; Lopes, T.; Orlando, B.; Scherer, C.; Nunes, M.; Araujo Duarte, G.; Bohlke, M. Comparative effectiveness of 30\% trisodium citrate and heparin locking solution in preventing infection and dysfunction of hemodialysis catheters: A randomized controlled trial (CITRIM trial). Infection 2017, 45, 139-145. [CrossRef] [PubMed]

23. Sofroniadou, S.; Revela, I.; Kouloubinis, A.; Makriniotou, I.; Zerbala, S.; Smirloglou, D.; Kalocheretis, P.; Drouzas, A.; Samonis, G.; Iatrou, C. Ethanol combined with heparin as a lockinging solution for the prevention of catheter related blood stream infections in hemodialysis patients: A prospective randomized study. Hemodial. Int. 2017, 21, 498-506. [CrossRef] [PubMed]

24. Winnicki, W.; Herkner, H.; Lorenz, M.; Handisurya, A.; Kikic, Z.; Bielesz, B.; Schairer, B.; Reiter, T.; Eskandary, F.; Sunder-Plassmann, G.; et al. Taurolidine-based catheter locking regimen significantly reduces overall costs, infection, and dysfunction rates of tunneled hemodialysis catheters. Kidney Int. 2018, 93, 753-760. [CrossRef]

25. Jadad, A.R.; Moore, R.A.; Carroll, D.; Jenkinson, C.; Reynolds, D.J.M.; Gavaghan, D.J.; McQuay, H.J. Assessing the quality of reports of randomized clinical trials: Is blinding necessary? Control. Clin. Trials 1996, 17, 1-12. [CrossRef]

26. Wells, G.; Shea, B.; O'Connell, D.; Peterson, J.; Welch, V.; Losos, M. Newcastle-Ottawa Quality Assessment Scale; Ottawa Hospital Research Institute: Ottawa, ON, Canada, 2013.

27. Higgins, J.P.; Thompson, S.G. Quantifying heterogeneity in a meta-analysis. Stat. Med. 2002, 21, 1539-1558. [CrossRef]

28. Moher, D.; Liberati, A.; Tetzlaff, J.; Altman, D.G. Preferred reporting items for systematic reviews and meta-analyses: The PRISMA statement. PLoS Med. 2009, 6, e1000097. [CrossRef]

29. Buturovic, J.; Ponikvar, R.; Kandus, A.; Boh, M.; Klinkmann, J.; Ivanovich, P. Filling hemodialysis catheters in the interdialytic period: Heparin versus citrate versus polygeline: A prospective randomized study. Artif. Organs 1998, 22, 945-947. [CrossRef]

30. Dogra, G.K. Prevention of Tunneled Hemodialysis Catheter-Related Infections Using Catheter-Restricted Filling with Gentamicin and Citrate: A Randomized Controlled Study. J. Am. Soc. Nephrol. 2002, 13, 2133-2139. [CrossRef] 
31. Betjes, M.G.; van Agteren, M. Prevention of dialysis catheter-related sepsis with a citrate-taurolidine-containing locking solution. Nephrol. Dial. Transplant. 2004, 19, 1546-1551. [CrossRef] [PubMed]

32. Nori, U.S.; Manoharan, A.; Yee, J.; Besarab, A. Comparison of low-dose gentamicin with minocycline as catheter locking solutions in the prevention of catheter-related bacteremia. Am. J. Kidney Dis. 2006, 48, 596-605. [CrossRef] [PubMed]

33. Solomon, L.R.; Cheesbrough, J.S.; Ebah, L.; Al-Sayed, T.; Heap, M.; Millband, N.; Waterhouse, D.; Mitra, S.; Curry, A.; Saxena, R.; et al. A randomized double-blind controlled trial of taurolidine-citrate catheter lockings for the prevention of bacteremia in patients treated with hemodialysis. Am. J. Kidney Dis. 2010, 55, 1060-1068. [CrossRef]

34. Filiopoulos, V.; Hadjiyannakos, D.; Koutis, I.; Trompouki, S.; Micha, T.; Lazarou, D.; Vlassopoulos, D. Approaches to prolong the use of uncuffed hemodialysis catheters: Results of a randomized trial. Am. J. Nephrol. 2011, 33, 260-268. [CrossRef]

35. Chen, F.K.; Li, J.J.; Song, Y.; Zhang, Y.Y.; Chen, P.; Zhao, C.Z.; Gong, H.Y.; Yao, D.F. Concentrated sodium chloride catheter locking solution-A new effective alternative method for hemodialysis patients with high bleeding risk. Ren. Fail. 2014, 36, 17-22. [CrossRef]

36. Jaffer, Y.; Selby, N.M.; Taal, M.W.; Fluck, R.J.; McIntyre, C.W. A meta-analysis of hemodialysis catheter lockinging solutions in the prevention of catheter-related infection. Am. J. Kidney Dis. 2008, 51, 233-241. [CrossRef]

37. Labriola, L.; Crott, R.; Jadoul, M. Preventing haemodialysis catheter-related bacteraemia with an antimicrobial locking solution: A meta-analysis of prospective randomized trials. Nephrol. Dial. Transplant. 2008, 23, 1666-1672. [CrossRef]

38. Moran, J.E.; Ash, S.R. Lockinging solutions for hemodialysis catheters; heparin and citrate-A position paper by ASDIN. Semin. Dial. 2008, 21, 490-492. [CrossRef] [PubMed]

39. Vanholder, R.; Canaud, B.; Fluck, R.; Jadoul, M.; Labriola, L.; Marti-Monros, A.; Tordoir, J.; Van Biesen, W. Catheter-related blood stream infections (CRBSI): A European view. Nephrol. Dial. Transplant. 2010, 25, 1753-1756. [CrossRef]

40. Jenks, M.; Craig, J.; Green, W.; Hewitt, N.; Arber, M.; Sims, A. Tegaderm CHG IV Securement Dressing for Central Venous and Arterial Catheter Insertion Sites: A NICE Medical Technology Guidance. Appl. Health Econ. Health Policy 2016, 14, 135-149. [CrossRef]

41. Yahav, D.; Rozen-Zvi, B.; Gafter-Gvili, A.; Leibovici, L.; Gafter, U.; Paul, M. Antimicrobial locking solutions for the prevention of infections associated with intravascular catheters in patients undergoing hemodialysis: Systematic review and meta-analysis of randomized, controlled trials. Clin. Infect. Dis. 2008, 47, 83-93. [CrossRef] [PubMed]

42. Yon, C.K.; Low, C.L. Sodium citrate $4 \%$ versus heparin as a locking solution in hemodialysis patients with central venous catheters. Am. J. Health Syst. Pharm. 2013, 70, 131-136. [CrossRef] [PubMed] 